\title{
VICENTE RIVA PALACIO *
}

\author{
P O R \\ CLEMENTINA DIAZ Y DE OVANDO
}

A Juan Antonio Ortega y Medina

TJustamente olvidado, Vicente Riva Palacio es una de las personali1 dades más dignas de estudio en el panorama de la literatura nacional del siglo xix. Su obra abundante y variada: poesía, drama, novela, cuento, crítica, lo revela como uno de los más completos e interesantes escritores liberales, de aquellos que, como ha dicho Andrés Henestrosa, fueron escritores y soldados y para quienes la Patria fue una constante preocupación, pues la habían visto a punto de zozobrar, de sucumbir, y hasta la palabra Patria tuvo para ellos una connotación dramática, desconocida para los escritores de hoy.

Es esta preocupación de Vicente Riva Palacio por la Patria la que pretendo destacar aquí, comentando un pequeño y casi ignorado texto, Cuentos de un loco, que publicó La Orquesta en su folletín el año de 1874, y cuyo conocimiento debo a la generosidad de mi maestro Francisco González Guerrero.

No se me escapa que tema más propio para esta charla sería la vida de Riva Palacio, llena de divertidas anécdotas, o el señalar alguno de los aspectos más significativos de su obra, por ejemplo, su estupenda labor crítica. Pero al comentar Cuentos de un loco deseo, en este año en que México conmemora el primer centenario de la Batalla del Cinco

* Conferencia leida en la Sala Manuel M. Ponce el 13 de julio de 1962, dentro del ciclo de conferencias "Examen de Escritores Mexicanos". 
de Mayo, rendir de esta manera, homenaje a quien como Vicente Riva Palacio supo, tan cabalmente, con la acción y con la idea, defender a México de una agresión extranjera.

El 19 de junio de 1867, México triunfaba en Querétaro de la Intervcnción y el Imperio. La victoria clesató de inmediato una serie de insultos y calumnias contra nuestro país. Algunos escocieron más que otros, tal el libro de José Zorrilla El Drama del Alma que se consideró como una traición a la hospitalidad mexicana. El libro de Zorrilla lo publicó en su folletín el ultraconservador periódico El Pájaro Verde, el año de 1872; y ese mismo año, el diario El Correo del Comercio, en su edición de 26 de mayo decía: "Los escritores franceses no se cansan de deturpar a México", y consignaba la traclucción de un injurioso artículo contra México que la Revue des Deux Mondes acababa de publicar acusándonos como era de rigor, de los peores crímenes, ser de raza hibrida: india y española y, por lo mismo, "rebeldes a toda civilización", inhábiles para vivir sin la revolución y el cuartelazo. Este artículo de la Revue des Deux Mondes fue contestado inteligentemente en El Americano, de París, por José Díaz Covarrubias, entre otras razones arguye la ignorancia que Francia tiene de las cosas de México, ignorancia que tan cara le habia costado, su incomprensión para nuestras revoluciones que no son de pillaje sino de ideas y en cuanto a que México formaría parte de la Unión Americana, no pasaba de ser un vaticinio de bastante mala fe.

Tampoco calla ante las infamias que nos endilga la Revue des Deux Mondes el editorialista de El Correo del Comercio, quien el 29 de mayo le recuerda a ésta lo cruento de las guerras civiles en Francia, el Código negro de Argelia, y después de hacer un cletallado inventario de todas las tropelías y brutalidades cometidas por la culta y civilizada Francia clurante la Intervención y el Imperio, termina con la seguridad de que la enorme injusticia que Francia cometió con México no quedará impune.

"Estos son hechos -dice-- y hechos muy recientes que conoce la Europa y la América, y hechos que no quedarán impunes. La cuestión es de ticmpo."

Y la impunidad terminó; llegó el día de la expiación del crimen cometido por Francia, por Europa, contra nuestro ser político; crimen 
que para aquellos defensores de la patria era imposible que quedara sin castigo, tarde o temprano se nos haría justicia.

En 1868 en Calvario y Tabor, novela que es la epopeya del pueblo donde reluce el valor, la generosidad de esos humildes protectores de México: los chinacos, o chinacates, que sabían morir como los buenos, Riva Palacio profetizaba: Dios, la historia y el porvenir nos darán el triunfo, y la ejecución de ese castigo en que Dios y la Historia intervinieron para darnos el triunfo es el tema que el año de 1874 desenvuelve en Cuentos de un loco.

Cuentos de un loco no es propiamente una novela sino más bien un relato, el formalista erudito pronto encontraria en su estructura esas fallas características de la novela romántica del siglo xix, le pondría muchos reparos y no la aceptaría como tal. Pero en esta clase de relatos o novelas del siglo xix, y en esto hay que hacer hincapié, lo importante no es la estructura ni el primor de la forma, lo fundamental y valioso son las ideas, el mensaje, pues lo que interesa al autor es que este mensaje llegue a los lectores y sea por ellos comprendido y aceptado.

En Cuentos de un loco, Riva Palacio cuida la estructura que consta de doce capítulos bien equilibrados, escritos en prosa limpia y fácil, pero el énfasis lo pone, naturalmente, en Ias ideas, en el mensaje, y gracias a este intencionado énfasis, que es aquí lo preciado, el relato Cucntos de un loco, constituye un excelente documento literario para el estudio de la defensa de esa calumnia contra América, contra México, que tiene su origen en el viejo problema que es la negación de nuestro ser histórico por Europa y que arranca desde el momento en que, sin que se nos esperara, irrumpimos aquel 12 de octubre de 1492 ante los ojos de Colón, de este imaginativo siempre dispuesto a transfigurar la realidad.

Y para dejar claras las ideas que Riva Palacio expone en Cuentos de "n loco aludiré, aunque sea a grandes trazos, a este problema que ha estudiado Edmundo O'Gorman en su libro Idea del Descubrimiento de América.

Para nuestro infortunio, ningún historiador o geógrafo griego, ni romano, ni la Biblia, ni los Padres de la Iglesia, habian nombrado estas tierras ni menos mentado a sus habitantes, no teníamos, por lo mismo, casillero donde quedar encerrados; nada más fácil que negar nuestro ser histórico y empezó entonces la difamación y la calumnia de América, que será vista, como elocuentemente rimaba el pícaro y poeta Mateo 
Rosas de Oquendo, que por estos rumbos había andado en los inicios del siglo xvir, como tierra maldita que perturba y pervierte al español:

Es tierra de confusión,

Es caos do están las marañas

es un infierno de vivos

$y$ un anticristo en palabras.

Y también todos nuestros males partieron de esa negación, clamaba un indio en el Auto de las Cortes de la Muerte (1557), Auto estudiado y analizado con esa perspicacia que le es característica por Juan Antonio Ortega y Medina en su excelente ensayo: "El indio absuelto y las Indias condenadas". I

Con voz de conciencia popular española el indio del Auto de las Cortes de la Muerte, se dolía de que el griego Tolomeo no hubiera señalado al indígena un sitio en el esquema tradicional cristiano:

Tolomeo que heciste tan gran suma y conduta de naciones, y escrebiste, di ¿cómo no nos pusiste en tu registro y minuta?

Antiguos que trastornastes al mundo y al retortero le trajistes y pintastes, ¿y cómo nos olvidastes (os pregunto) en el tintero?

¿Cómo no distes noticias de nuestras tierras? (os pido).

El olvido de Tolomeo, de los antiguos, España lo remedió con la cristianización, por medio de ella pudimos entrar, aunque a regañadientes, a la cultura occidental.

Si la religión nos dio humanidad, también la poesía hizo un esfuerzo por otorgarnos la universalidad que nos era tan decididamente negada. Ya lo ha dicho el filósofo "sólo la poesía da nombre a lo existente".

1 Historia Mexicana. Vol. Iv, No 4, abril-junio, 1955. p. 477. 
Alonso de Ercilla y Zúñiga, poeta del Renacimiento, abrevado en las fuentes clásicas, testigo y actor en la conquista de Chile, relata los hechos de esta sumisión, y en su poema La Araucana los verdaderos héroes son los indios y los antihéroes los hispanos. En el entusiasmo por la valentía, el arrojo de los araucanos, el poeta no puede menos que compararlos con los héroes de la antigüedad clásica. Lautaro resulta más digno de admiración que los Publios Decios, que Curcio, Scévola y Leónidas, Furio y Marcelo:

\section{Decidme: ‘estos famosos que hicieron que al hecho de este bárbaro igual fuese?}

La constancia y la fe de los araucanos es utilizada por Ercilla en otra comparación clásica: la historia de la Reina Dido. La india Lauca es equiparada a Dido, y Caupolicán queda implicado en esta espléndida trinca de héroes y de dioses: Caupolicán-Marte-Cupido.

Ercilla parangona a los indios del Arauco con los héroes grecorroma. nos y esta comparación no es arbitraria, tiene un noble propósito pues al comparar a estos indios que difícilmente podfan encajonarse dentro del esquema de la cultura tradicional cristiana, con los héroes de la antigüedad clásica, los ha occidentalizado, humanizado, y aún los lleva más allá, los hace entrar a la gran poesía mítica con la majestad, la dignidad, el valor y hasta con la serena belleza de un héroe griego.

$\mathrm{Y}$ aunque Ercilla jura en su poema atenerse a la verdad de los hechos, crea también en La Araucana un nuevo cuento que habla por primera vez poéticamente de América: América le sirve para la creación de un tema artificioso e imaginativo, donde los personajes indios se codean con los personajes de la antigüedad clásica. Ercilla, gracias a su volutad poética, hace de América una tierra de maravillas, y así nuestra América se salva en lo positivo por esa potencia poética.

Pero esta visión de América, portentosa, sugestiva e idealizada no prevaleció, triunfó la visión de América como tierra de maldición e infamia, sustentada, como en el siglo xvirl afirmaba nuestro gran humanista Francisco Javier Clavijero, en el "más cicatero patriotismo, en la ignorancia y mala fe europeos".

La calumnia no disminuyó con el tiempo, mucho arreció cuando nos independizamos, cuando traicionamos la oportunidad de ser occidentales, que España nos había otorgado con su dominación.

Una nueva coyuntura de entrar a la cultura occidental se presentó 
para México el año de 1862. Ahora era Francia la que nos tendía la mano, la que se presentaba como nuestra redentora, pues España, es cierto, hizo lo posible por salvarnos, por redimirnos, sin embargo, su redención fue un poco a medias y bastante deslucida; al fin $y$ al cabo, para la conciencia europea Africa comienza en los Pirineos. En cambio, Francia era a la sazón la guía cultural del mundo, políticamente la nación más poderosa y uncidos en su carro la salvación sería completa, puestos, como ahora se dice, en órbita, en la órbita de la raza latina se nos salvaría también de la ambición yanqui. ¿Qué importaba que la salvación tuviera un alto precio? Qué importaba que encubriera el ¡negociote! de los bonos Jecker, la posesión como colonia francesa de Sonora y Baja California, la explotación de las minas, en suma, el ser tributarios de Francia. ¡Bien valía París una misa! La justificación ante los ojos del mundo resultaba hábil y perfecta: de pueblo salvaje, incivilizado, incapaces de gobernarnos, con el doble estigma, según decía la Revue des Deux Mondes, de ser descendientes de indios y españoles pasaríamos a seres civilizados y entraríamos por la espaciosa puerta del prestigio francés a la universalidad.

Insensatez sería no aceptar la mano que se nos tendía. Cuán significativo es este párrafo de la proclama que el almirante Jurien de la Gravière y el embajador Dubois de Saligny firmaron el 16 de abril de 1862:

"La bandera de Francia ha sido plantada sobre el suelo mexicano y no retrocederá jamás: que los hombres prudentes la acojan como una bandera amiga: ¿qué los insensatos se atrevan a combatirla!

Mascando la humillación y el rencor en $1869 \mathrm{M}$. d'Hericault, en su libro Maximilien et Mexique, culpa a estos insensatos que se levantaron contra Francia de haber malogrado la última oportunidad de salvación que tuvo México:

"Perdimos en esto, políticamente nuestra buena fama de altivez, militarmente nuestra fama de generosidad, de bondad y justicia. Los mexicanos que no tenían nada que perder, no perdieron nada, sino es quizás, la última sobra de modestia que les quedase, es decir, la última probabilidad de salvación. * Hoy que han matado a un

* La cursiva es mía. 
príncipe europeo, que han aplastado a la Francia y hecho retroceder a los Estados Unidos; hoy que son héroes y magnánimos, es imposible prever hasta qué límites siniestros y bufos llevarán el carnaval de su anarquia". ${ }^{2}$

Riva Palacio fue uno de aquellos imprudentes que se aprestó a demostrar ante la jactancia europea nuestra madurez. Cuando la causa de México obtuvo la victoria, cuelga la espada, pero sigue en la brega, ahora con un arma acaso más eficaz que la espada: la pluma, para deshacer ese entuerto que es la calumnia europea contra México y exhibir ante el mundo entero no sólo la injusticia de la intervención tripartita que reclamaba castigo, sino también señalar la igualdad de nuestro ser histórico con Europa, paridad que se nos negaba.

$\mathbf{Y}$ Riva Palacio en Cuentos de un loco justificará nuestra igualdad histórica con Europa.

El relato empieza con un versículo del "Libro de los Proverbios" que está de acuerdo con el tema: "No digas: yo me vengaré. Espera en el Señor, y El te salvará". A seguidas va la dedicatoria a la Patria escrita con esa emoción, con ese sentimiento que le es privativo:

"Patria: Tu amor me alienta, tuyos son mis pensamientos y mi corazón, el destino me hace extranjero entre tu pueblo, por cuya libertad he luchado; pero mi vida te pertenece. El mayor crimen de este siglo ha sido la tentativa contra tu ser político: los poderosos se congregaron contra tí, tus hijos te salvaron. Dios castigó terriblemente a tus enemigos.

Este es el compendio de la historia que torpe va a bosquejar mi pluma".

En el capítulo primero llamado "El viajero" recurre al espiritismo, muy de moda en su tiempo. Desde su época de general chinaco, cuenta Eduardo Ruiz en su Historia de la guerra de intervención en Michoacán, asombraba a sus soldados con el anuncio de sucesos que luego resultaban ciertos y que, según decía, se los comunicaba un espíritu.

En este primer capítulo presenta al personaje, un espíritu, y por su boca Riva Palacio hace alusiones cosmogónicas: la tierra átomo iluminado por un pequeño sol, el universo entero es nada ante Dios;

2 México a tratés de los siglos. "La Reforma". T. v., p. 862. (Edición de 1953). 
en todos los capítulos hará constantes referencias a la grandeza divina que, como pronto veremos llevan la intención de dar mayor importancia al castigo que Dios hará con las naciones agresoras de México. En Cuentos de un loco, Dios es el personaje principal, aunque no aparece, actúa en su papel de justiciero al través del artificio literario del autor.

El espíritu cuenta su historia: es la de un hombre muerto en un naufragio una mañana de abril en que el mar estaba tranquilo y nada hacía presentir la catástrofe. El barco, un buque mixto de velas y vapor es el representante del progreso; los pasajeros gozaban de todas las comodidades que el progreso trae consigo; un poco irónicamente Riva Palacio al comentar el desastre, se ríe de esa seguridad que daba el progreso, es un poco hacer burla de esa bandera del progreso positivista que ya se insinuaba y que llegaría a ser el tono de su época. La ordenación del munda progresista se rompe y Riva Palacio opone a éste su imagen krausista en el segundo capítulo "Entre espíritus".

Las ideas que en este segundo capítulo expone sobre el espíritu, la materia y Dios, caen dentro de la filosofía krausista, filosofía que Riva Palacio debió haber conocido por 1870 cuando estuvo en España, ya para aquellos años muy difundida en la Península gracias a Julián Sanz del Río. El krausismo fue la puerta de conocimiento por la cual España pretendió entrar a la modernidad, pero más valioso que ese conocimiento fue -dice Joaquín Casalduero- "la integridad moral que lo acompañaba. El español había perdido por completo la sensibilidad moral con respecto a la vida del pensamiento y a toda función pública, Sanz del Río inculcó ese ideal de respeto de sí mismo, y por tanto a los otros, juntamente con el cumplimiento del deber". El krausismo en su modalidad pedagógica española era un ideal bien adecuado al sentir de Riva Palacio, que años después en 1882 , emprenderá con sagacidad, ironía, gracia y mucho talento la defensa de la filosofía krausista en contra del positivismo.

En el tercer capítulo Riva Palacio hace alarde de sus conocimientos sobre astronomía, proporciona datos sobre la velocidad de las estrellas, de la luz; sus ideas astronómicas reconocen como fuente las de Flamarion, ideas que aquí divulga. Como seguidor del panteísmo en esta divulgación quiere acabar con la tradición escolástica, liquidar las viejas telarañas de esta tradición cuyas ideas sobre astronomía aún perduraban. Esta propaganda de las nuevas ideas astronómicas le sirve como instrumento político de sus ideas. 
El capítulo cuarto lo dedica a la alabanza de Dios, claro que no es el dios ortodoxo sino el del krausismo en cuyos atributos se detiene largamente. Estos conceptos religiosos del krausismo van envueltos de tal manera que el lector común y corriente quedaría muy satisfecho de tanto como se alababa a Dios. Y mientras se aclaraba si era el dios ortodoxo o el dios krausista, el lector ya se había tragado el propósito de Riva Palacio: Dios estaba de parte de estos liberales acusados de ateísmo y no de los conservadores que habian propiciado Ia intromisión extranjera.

En el capítulo quinto presenta otro personaje: el ángel de México; tanto el ángel como el espíritu son los testigos de la justicia divina, su papel es el de contemplar y asombrarse ante el castigo que Dios ejecuta.

El ángel servirá de guía al espíritu, recuerdo muy dantesco. El aspecto del ángel, dice el espíritu:

era encantador pero triste y melancólico. Debía llenar una misión triste también; seguíle impulsado por una irresistible simpatia, porque aquel ángel era uno de los custodios de la tierra, y era el ángel de mi patria, era el ángel de México.

Riva Palacio aprovecha la oportunidad para hablar exaltadamente de la patria y del amor que se le profesa, amor que no termina ni con la muerte.

Este ángel es melancólico y triste porque conoce la historia, porque sabe lo que ha acontecido, viene a ser la conciencia de la historia que habla por su boca.

El ángel se apresura a cumplir su misión: guiar al espiritu a la tierra, para mostrar tanto el crimen que se ha cometido con México como el castigo. Y no sin hacer una vez más gala de sus conocimientos astronómicos, Riva Palacio nos dice cómo el ángel y el espíritu salvan la enorme distancia que los separa de la tierra, a la que ven flotando en el éter, iluminada por el sol. A medida que van acercándose empiezan a distinguir los continentes, los mares, los gigantescos ríos: el Amazonas y el Mississippi, los desiertos; y no puede menos en un arraque de orgullo que admira el poder de la ciencia, la inteligencia del hombre que ha sometido a las fuerzas de la naturaleza.

¿Quién diría a Riva Palacio que antes de un siglo el hombre podría ver la tierra como la contemplaron el ángel y el espíritu! 
Los ojos del espíritu descubren América, como buen romántico Riva Palacio se deleita en la pintura del paisaje americano. Por fin el ángel y el espíritu divisan México: el cuadro no podía ser más sombrio y desolador, en todo el país "la guerra", la pesadumbre; México sufría una invasión extranjera, era a la sazón un pais esclavo; y lo más indignante -comenta el espíritu- era la alegría que reinaba en la capital adornada con gallardetes y banderas, "las campanas de los templos lanzadas a vuelo hacían oir su estrepitoso clamoreo"; los cañones sus salvas, los cohetes su estallido; "era la alegría de un pueblo que en vez de llorar su honra perdida celebraba el gran día de su vergüenza".

"Sin embargo - continúa narrando el espíritu - cerca de la ciudad engalanada todavía luchaban los que no querían ser esclavos ni abyectos, pero la muerte triunfaba de su esfuerzo. Quise pedir una explicación de todo ésto al ángel; alcé el rostro para mirarle otra vez y él me mostró silenciosamente la capital.

"Entonces ví en medio de las tropas formadas, atravesar un tren regio, y en él un hombre y una mujer, los dos jóvenes, los dos hermosos, los dos con un aspecto distinguido; y sin embargo, sobre aquellas dos magníficas frentes habia ya el signo del inmenso infortunio...

“-Los emperadores, -me dijo el ángel solemnemente-, Maximiliano y Carlota.

"-iPobres espíritus hermanos míos -exclamé- encarnados para la expiación y el sufrimiento! ...

"Y ví en México hombres y soldados de Francia, de Austria, de Bélgica; y sentí la influencia para sostener aquel trono, de España, y de Inglaterra, y de Roma; y México estaba solo, y un puñado de hombres se agrupaba en derredor del estandarte de la independencia, pero sobre ellos tendía sus alas el ángel de la fe, y en torno a ellos se cernían innumerables espíritus de mártires sacrificados en los cadalsos y en los combates.

"Pero también el espíritu de la victoria abandonaba las banderas de México y colgaba sus frescos laureles en los pendones de la invasión...

"Un hombre se hubiera quizá quejado de la Providencia al contemplar lo que pasaba en México. Los espíritus, sin poder penetrar el porvenir, no se atreverían a dudar un instante de la justicia eterna. 
“-¡Dios es la eterna justicia! -exclamó el ángel- leyendo mis pensamientos.

"Yo me estremecí, y perdí de vista cuanto me rodeaba, abismado en la contemplación de Dios".

Y en el capítulo "Luz del espacio", el ángel mirando con ternura al espíritu le dice cómo ya se ha consumado el sacrificio de México, pero gracias a la justicia divina, el crimen no quedará sin punición.

"Cuantos poderosos han contribuido a humillar al débil serán tocados por el ángel de los castigos. México volverá a ser libre y honrado".

A seguidas el espíritu pasa a explicar la manera cómo los espíritus pueden ver las "cosas que han pasado sobre alguno de los mundos, de esa sucesión de tiempo sin la cual los hombres no pueden entender la historia". A los espíritus les es posible mirar los sucesos simplemente por la combinación de las propiedades de la luz, y claro, de la poderosa fuerza de vista de los espíritus.

Riva Palacio se solaza en una erudita disertación científica sobre la velocidad de la luz; cómo el rayo luminoso que nos hace ver la estrella polar no es el rayo que en esos momentos sale de ella, sino el que partió hace medio siglo, y para que sus lectores comprendan ésto con mayor claridad recurre a la fotografia, novedad en su tiempo, lo mismo que a la linterna mágica; estas novedades le son válidas como metáforas para divagar sobre las novedades científicas del momento y demostrar que está al día.

La larga exposición de las ideas astronómicas en las que se estanca demasiado, sirve a Riva Palacio para hacer reflexiones históricas, así el rayo luminoso es el recurso de que se vale para presentar los succsos históricos que le interesa destacar, y poder mostrar ante nuestros ojos cuadros históricos que vienen a ser diversas proyecciones, estampas que le es dable poner y quitar a discreción. Merced a este arbitrio muestra los acontecimientos pasados y da a conocer la historia de los países que intervinieron en la guerra de México; describe los campos de batalla con imágenes muy conocidas; comenta la historia de esas naciones, su evolución social y política, que es, como toda evolución, siempre trágica, siempre dramática: guerra, destrucción y muerte.

¿Por qué entonces, se preguntaría Riva Palacio, tanta alharaca de 
los países europeos por las revoluciones en que México se buscaba a sí mismo? Si la historia de esos países como repasaba La Orquesta de 9 de abril de 1862, en el romance "El trono de México" era bastante turbia, y con hechos, entre otros como la noche de San Bartolomé, la Guerra de las Rosas y los recientes sucesos de la guerra carlista, hechos que pese a nuestro salvajismo aún no ocurrían en México:

.. Y Y no se acuerda la Iberia
que en nombre de libertad
se arrasaron los conventos
sin temer a Satanás,
y se ahorcaron a los frailes
y a las monjas ... ? arre allá...
y se hicieron mil lindezas
que no quiero recordar.
Porque la Francia y España
e Inglaterra olvidan ya
la paja en el ojo ajeno,
y nos quieren conquistar
porque en unos cuantos años
hemos conseguido más
que en siglos esas naciones
con más sangre y más penar...

Volvemos a Cuentos de un loco, en el capítulo "Lluvia de sangre" el espíritu mira una ciudad destruída por la guerra: Querétaro; la muerte silenciaba la ciudad, el ángel y el espíritu presencian el castigo de Maximiliano, Miramón y Mejía.

"Se levantó una nubecilla de humo, sonó una detonación, y los tres espíritus se lanzaron al espacio...- Comienza la expiación! -exclamó el angél-. Entonces de la sangre de aquellos hombres se alzó un vapor denso, y al mismo tiempo volvió a aparecer fresca en todo el país la sangre derramada en aquella inicua guerra. |Oh! era la República como un lago rojo, y ese lago hirvió, y la sangre sé tornó en vapor también, y todos los vapores se condensaron y formaron una nube negra, que cruzando el Altántico se dirigió a Europa.

"Seguí instintivamente aquella nube, y la vi detenerse en Paris". 
En Paris se celebraba la "primera exposición universal de la industria de los hombres" convocada y reunida por Francia, allí estaba toda la nobleza europea, todos los hombres notables del mundo, y en aquel momento en que la soberbia se encuentra en su apogeo, sobreviene el desastre: Napoleón recibe la noticia de la muerte de Maximiliano:

"Y la nube condensada -asevera el espíritu- comenzó a desatarse en una lluvia de sangre que bañó al hombre Napoleón III.

"La Francia se estremeció hasta las profundidades de su suelo al sentir aquellas gotas de sangrienta lluvia, porque los pueblos sufren muchas veces por los crímenes de sus gobernantes".

La guerra con Prusia había llegado, la expiación continuaba en tolo su rigor.

En el capítulo "Roma" el ángel cada vez más triste conduce al espíritu a esta ciudad en donde iba a presenciar -dice éste- otro cuadro sombrio de aquel drama terrible.

$\mathrm{Y}$ dueño Riva Palacio, como hemos visto, del artilugio del rayo luminoso, empieza a desenvolver la historia de Roma desde sus comienzos: la fundación de la ciudad, el rapto de las sabinas, la República y el Imperio, los bárbaros y más tarde, el reinado de los papas, la grandeza de la cristiandad.

“¡Roma! -exclama el espíritu- ¡Cuántos recuerdos! ¡Cuántas tradiciones! ¿Cuánta significación tiene ese nombre para las civilizaciones modernas y para la historia de la humanidad de los últimos siglos!"

Pero Roma ya no tiene -se duele el espíritu- la grandeza ni el poderío de los siglos anteriores.

Riva Palacio, hombre de amplia cultura, se detiene en la historia y en la descripción cle la Basílica de San Pedro, en su asombroso arte, recuerda a Bramante, a Rafael y a Miguel Angel; este elogio y el del Vaticano tiene también otra intención: el Vaticano forma parte del escenario en que se desenvuelve el capítulo "La última lágrima", y aquí, en el Vaticano, que tampoco fue ajeno al drama de México, en el asiento mismo de la cristiandad, la justicia divina abate su rayo sobre Carlota. 
El ángel traslada ahora al espíritu a España, en el capítulo "Un día y muchos días". El espíritu lleno de extrañeza pregunta si hay alli culpables, pues las tropas españolas al mando del general Prim se retiraron de México. El ángel responde que sí, la culpable es Isabel II, cuyas tropas salieron de México porque no pudo conseguir que el trono de este país fuera ocupado por uno de los Borbones.

El ángel y el espíritu ven ante sus ojos la ciudad de Madrid, capital de España, -aclara el espíritu- "merced a la energía e indomable voluntad de ese espíritu tan estudiado y tan poco comprendido que se llamó Felipe II".

Recordemos que por allá había andado Riva Palacio en 1870 y no es posible que se dejara en el tintero sus impresiones; hace referencias a los cafés y a los teatros, a la alegría de la gente.

De nuevo, mediante el procedimiento del rayo luminoso proyecta la historia de España desde los primeros siglos: Ia lucha entre cartegineses y romanos, la llegada de los suevos y visigodos; más tarde la invasión musulmana y la resistencia y triunfo de los cristianos; después el esplendor español en la época de Carlos $V$.

Pero ¿qué se hizo la grandeza de España? aquella que Hernando de Acuña sintetizó en maravilloso renglón:

$$
\text { "Un monarca, ni imperio y una espada". }
$$

¿Qué fue de su poderío? ¿Qué se hicieron su orgullo y su riqueza? ¿Qué las proezas de sus grandes capitanes? Todo se triza en manos de Isabel II, agresora de México.

El espíritu la ve en Irún partir desterrada rumbo a Francia; también presencian su partida los espíritus de los reyes y de los hazañosos capitanes que observan apesadumbrados hundirse el trono del vencedor de Francisco 1 .

"Tomó parte activa -insiste el ángel- en la negra conjura que tramaron contra México los poderosos.

$$
\begin{aligned}
& \text { "Mira dijo el ángel, } \\
& \text { y miré }
\end{aligned}
$$

levantarse el vapor sangriento de la guerra civil".

En el último capítulo "Un crimen misterioso", el espíritu alude una vez a la bulliciosa vida nocturna de Madrid. Sin embargo, esa noche 
en que el ángel y el espíritu regresan a Madrid no hay tal bullicio, la noche es negra, la nieve está al caer, las calles solas, y el viento del Guadarrama gime agitando "apenas las hojas de los árboles con un murmullo imperceptible"; es el escenario romántico propicio a la representación de un drama. Una vez preparado el escenario, el espíritu a la manera del diablo cojuelo, ve al través de los techos y de los muros de los palacios y de las casas, la agitación que prevalece: un rey extranjero, Amadeo de Saboya, va a gobernar España y la agitación culmina en un asesinato.

"Algunos días más tarde -cuenta el espíritu- un féretro salía del Ministerio de Guerra y era depositado en la Basílica de Atocha; dentro iba el cadáver del general Prim".

Por las calles - aunque no lo diga el espíritu- se recitaba ya el romance de la muerte del conde de Reus, romance que no se distingue de un corrido mexicano:

En la calle del Turco lo mataron a Prim, sentadito en su coche de una manera vil.

Cuatro tiros le dieron en mitad del corazón, cuatro tiros le dieron a tiro de cañón.

Al pasar por las Cortes le dijeron a Prim "vaya usted con cuidado que le quieren herir".

Si me quieren herir que me dejen pasar para entregar mi espada a otro general.

¿Quién será ese tirano quién será ese bribón que ha matado a mi padre quién será ese traidor? 
El espiritu clemanda al ángel sobre la muerte de Prim:

"-¿Y por qué ha muerto así? - pregunté al ángel- ¿él también cra culpable?

"-Dios sabrá si lo era; pero ninguno de los que intervinieron en la guerra directa o indirectamente, y en una alta posición entre los hombres, ninguno dejará de pasar en el mundo por una terrible prueba. Dios es justo; pero sus juicios son incomprensibles, no sólo para los hombres sino aun para los espíritus más elevados. Los hombres llegarán a comprender algún día, que todos los actores de esa intervención de México, en ese gran delito del siglo, y sea cual fuere el papel que hayan clesempeñado, han de sentir los efectos de la justicia divina...

"El ángel remontó su vuelo, y yo le seguí tristemente: horrible es un crimen, pero es terrible el castigo.

"El ángel se detuvo. Estábamos sobre un campo de batalla.

"Siempre la guerra en el mundo de los hombres".

Riva Palacio en este su pequeño relato Cuentos de un loco, refiere la expiación de los agresores de México ¿cuáles son las ideas y cuál es el mensaje que hacen tan valioso este relato?

Empecemos por su idea de la historia que pone en boca del ángel y que es la clave del recado:

"Nada pasa en el mundo que sea efecto de la casualidad, y los acontecimientos grandes o pequeños entre los hombres, se enlazan entre sí de una manera tan misteriosa que lo mismo el hombre que el pueblo sienten el castigo..."

Nada ocurre por casualiclad, ha dicho Riva Palacio, el suceso nimio queda trabaclo, se enlaza a los grandes acontecimientos; idea que le sirve a maravilla para destacar la magnitud del suceso mexicano o sea la agresión padecicla por México, nación a quien la soberbia europea, como ya he señalado, ve desde siempre como bárbara e indigna de figurar en el concierto universal; y así, en virtud de esta idea de Riva Palacio, México, país insignificante y disminuido por los ojos europeos, adquiere de pronto relevancia y significación, se coloca en un primer 
plano, ya que al través del acontecimiento de México la historia universal se complica al reproyectarse sobre Europa: Francia, Roma, España el suceso mexicano, y por éste Dios castiga a esas naciones.

Riva Palacio nos guía por la historia de estos países que retrae hasta sus origenes, para de esta manera afirmar en el suceso de México la historia de toda Europa. Y la historia universal europea queda vinculada al suceso de la intervención tripartita en México. Gracias a esta idea México adquiere la universalidad, que como he indicado anteriormente, nos fue tantas veces negada; y más aún al ser capaz este acon. tecimiento mexicano de promover, de ejercitar la justicia divina alcanza sentido la historia universal europea.

México también logra categoría universal por medio de la justicia divina, frente a la inmensa injusticia que se le hizo; la historia universal europea pasa a estar en función del acontecimiento mexicano y las revoluciones que sufren Francia, Roma, España, vienen a ser la expiación al través de la justicia de Dios de los sucesos de la intervención.

Todos los actores han de pagar, aun en los casos dudosos como el del general Prim.

Asimismo, México logra la paridad histórica, siempre negada por las naciones europeas, sus atacantes; pasa de ser nación impulsada por la historia a ser impulsora de ella; de ser pasivo deviene a ser terriblemente activo, y como consecuencia de este cambio la guerra franco-prusiana y los otros castigos a las naciones que nos agredieron. $Y$ Riva Palacio va todavía más lejos, pues México no sólo está en igualdad con Europa sino se encuentra un paso más adelante; México, esta república liberal que tiene a Dios de su parte, claro está, ese nuevo dios krausista, para quien la república liberal, establecida por él es lo más justo, es el presente y acaso también el futuro; la historia mexicana es ahora cl sujeto más importante de la historia, en tanto que los imperios agresores representan el pasado, lo putrefacto y caduco; y como esas naciones se han atrevido a violar la justicia, Dios tiene que intervenir y castigarlas; la justicia divina tiene en Cuentos de un loco un sentido muy moderno, inmanente, se aplica sobre imperios y personas que han violado un sistema: el de la república, sistema sagrado, realidad auténtica, que es la república liberal, y como esta violación a la república liberal ha sido hecha por instituciones caducas, representaciones del pasado, este nuevo dios se venga llevando esos mismos principios republicanos a España, Italia, Francia. Así se cumple la justicia divina anunciada por el ángel. 
Hay en Cuentos de un loco un simbolismo moderno, de buen cuño, como son los descubrimientos científicos de su tiempo; las ideas astronómicas; el mundo moderno de la luz, de la velocidad y de la fotografía, simbolismo que auna a recursos tradicionales. Las ideas filosóficas las da a conocer a la manera española, es decir, no como un sistema preconcebido y riguroso, sino diluido en su obra literaria. El ingenuo truco de la novela romántica del siglo xix en donde siempre trinfa el bueno $y$ se fulmina al villano aqui sublimado.

Cucntos de un loco es en su conjunto una de las más hermosas, inteligentes $y$ novedosas defensas literarias del principio de no intervención -hoy tan actual- y también defensa de México, de América, de la calumnia, del descrédito, que Europa forjó a nuestro derredor, y cn la que demuestra ante esta Europa engreída y soberbia la justicia que nos asistía, nuestra igualdad histórica y nuestra madurez.

Riva Palacio se ha curado el alma; pero la defensa de México iniciada años atrás no se detuvo en Cuentos de un loco, la hizo tarea de toda su vida. Su copiosa obra literaria es en su totalidad un alegato en pro de México, ya dando a conocer como quería el maestro Ignacio $\mathbf{M}$. Altamirano nuestro paisaje, nuestras costumbres, nuestra historia, insistiendo en la valía de nuestros literatos o bien rompiendo lanzas contra quienes menguaban la importancia de la literatura nacional que se cstaba forjando. Sus novelas coloniales, hoy desdeñadas e incomprendidas por la crítica, tienen el gran mérito de haber tomado como tema literario Ia Colonia y divulgar este pasado que, sombrío o no, forma parte de nuestro ser histórico. $Y$ además, en estas novelas dio la batalla por lograr esa actitud que ahora proclamamos y tanto nos enorgullece: tolerancia racial, espiritual e intelectual, tolerancia que es la que hace a los pueblos verdaderamente dignos de la universalidad.

En todos y cada uno de los géneros literarios que cultivó está presente México y su resguardo, pues como él mismo atestigua, hasta en el viento viento escuchaba el llamado de la patria: 
... Cuando era joven, tu rumor decía frases que adivinó mi pensamiento; y cruzando después el campamento, "Patria", tu ronca voz me repetía.

$\mathrm{Y}$ a ese conjuro de la Patria que rumoroso y angustiado el viento le traía, como en el verso de Garcilaso:

"tomando ora la espada, ora la pluma",

Vicente Riva Palacio, acudió siempre. 